GUERRA,DORR,FREITAS, v(11), no 11, p. 2462-2478 , JUN, 2013.

Rev. Elet. em Gestão, Educação e Tecnologia Ambiental (e-ISSN: 2236-1170)

\title{
A EFETIVIDADE DO HEDGE PARA O MERCADO DE BOI GORDO NAS PRAÇAS DO RIO GRANDE DO SUL
}

\section{THE HEDGE EFFECTIVENESS FOR LIVE CATTLE MARKET IN RIO GRANDE DO SUL SQUARE}

\author{
Renata Rojas Guerra ${ }^{1}$, Andréa Cristina Dörr ${ }^{2}$, Claílton Ataídes de Freitas ${ }^{3}$ \\ ${ }^{1}$ Universidade Federal de Santa Maria (UFSM) - Aluna de mestrado do Programa de Pós-graduação em Engenharia de \\ Produção - PPGEP. E-mail: renata.rojasg@gmail.com \\ ${ }^{2}$ UFSM - Profa. Adjunto do Departamento de Ciências Econômicas: andreadoerr@yahoo.com.br \\ ${ }^{3}$ UFSM - Profa. Adjunto do Departamento de Ciências Econômicas: Icv589@gmail.com
}

http://dx.doi.org/10.5902/223611708813

\begin{abstract}
RESUMO
Tendo em vista a importância desempenhada pecuária bovina no Estado do Rio Grande do Sul, buscou-se, através do presente estudo, averiguar se de fato a realização de operações de hedge no mercado futuro da BM\&F proporcionam resultados efetivos acerca da utilização desta como forma de mitigar os riscos provenientes das oscilações nos preços. Dessa forma, além de colaborar com o debate acadêmico no sentido de testar empiricamente uma ferramenta de análise de risco, o estudo também deixa uma contribuição para os pecuaristas do estado, os quais poderão utilizar tais informações como critério de decisão na elaboração de suas estratégias financeiras. Neste propósito, levantou-se a série temporal dos preços da arroba do boi gordo tanto para a praça em questão como para os contratos negociados no mercado futuro da BM\&F. A partir destas informações, e com base na teoria do portfólio, realizou-se uma série de testes econométricos, a fim de atestar a eficiência da utilização de operações de hedge. Foi estimado um modelo do tipo Var. Constatou-se que ambas as séries são estacionárias em primeira diferença e são co-integradas. Porém, as séries em análise levaram a resultados relativamente baixos quanto à razão ótima e efetividade do hedge, cerca de $5,61 \%$ e $12 \%$, respectivamente. Além disso, a razão ótima só é significativa a níveis de confiança superiores a $26,8 \%$. Isso sugere que esta não é uma adequada ferramenta de gerenciamento de riscos para os pecuaristas do Rio Grande do Sul. Desta forma, fatores como as condições edafo-climáticas, os custos inerentes à produção, e o próprio perfil empresarial dos produtores, os quais variam de acordo com a região analisada, poderiam justificar a incidência de resultados pouco expressivos.

Palavras-chave: mercado futuro, mercado à vista, gerenciamento de risco, operações de hedge
\end{abstract}

\begin{abstract}
Considering the importance performed by the cattle production in the Rio Grande do Sul state's economy, the objective of this study is to identify whether the operations done with regards hedge in the future market of the BM\&F provide effective results as a way to mitigate the risks arising from price fluctuations. The study aims to collaborate for the academic debate in the sense to test empirically a risk analysis tool. It also contributes for the farmers in the state, who may use this information as decision criteria to make financial strategies. In this regards, were gathered price time series of cattle for both Rio Grande do Sul and contracts negotiated in the future market traded in the BM\&F. With this information and based on the Portfolio Theory, were performed a series of econometric tests in order to prove the efficiency of using hedge. The model Var type was estimated. The results show that both series are stationeries in first degree and are co-integrated. However, the results of the series are relatively low with regards the optimal ratio and effectiveness of hedge with about 5,61\% and $12 \%$, respectively. Besides, the optimal ratio it only significant at confidence superior levels at $26,8 \%$. These findings suggest that this toll is not suitable to manage risks for cattle farmers in the state of Rio Grande do Sul. Therefore, factors as climatic conditions, the production cost, and the entrepreneurs' profile, which vary according the analyzed region, may justify the incidence of low expressive results.
\end{abstract}

Keywords: future market, spot market, risk management, hedge operation

\section{INTRODUÇÃO}

A produção de carne bovina é uma atividade predominante em varias regiões do Brasil. Dentre estas, destaca-se o estado do Rio Grande do Sul, o qual, sendo detentor de um rebanho de 14.478.312 de cabeças de gado é responsável por 6,81 do total produzido no país (IBGE 2011). 


\section{REGEXfUFSM}

Rev. Elet. em Gestão, Educação e Tecnologia Ambiental (e-ISSN: 2236-1170)

Desta forma, como o Brasil, além de possuir o maior rebanho comercial de carne bovina do mundo, ocupa a posição de maior exportador desde 2004, além disso, é importante destacar a relevância da participação da pecuária bovina gaúcha no que diz respeito às esferas global, nacional e local.

Neste contexto, os pecuaristas gaúchos, ao considerar os diversos fatores que influenciam a formação de preços da carne bovina no mercado em que estão inseridos, defrontam-se com risco de na data da venda deparar-se com um preço que não cubra seu custo de produção. Diante do exposto, torna-se evidente a necessidade do produtor de encontrar meios para proteger-se contra possíveis oscilações nos preços do bem em questão, ou seja, que lhe assegure um preço que, segundo suas estimativas, possa efetivamente recompensar seu investimento. Nesse contexto, é comum que os pecuaristas busquem métodos para minimizar riscos, de modo a assegurar a eficiência de suas atividades no campo.

Sendo o hedge uma ferramenta que permite a fixação antecipada do preço de venda do boi gordo, entre outras commodities, por meio de uma operação no mercado futuro, o pecuarista pode utilizá-lo como um seguro que garante a este um preço compatível com a atividade em questão, isto é, que seja capaz de cobrir seus custos de produção e ainda proporcionar uma margem de lucro. Deste modo, faz-se das operações no mercado futuro um método cujo intuito é compensar as variações dos preços no mercado físico.

Dentre os diversos estudos que avaliam a temática proposta, destacam-se o de Alves (2010), que analisou a efetividade e razão ótima de hedge e cross-hedge para o boi gordo e bezerro respectivamente, Monteiro et al. (2010), que avaliaram a não efetividade do hedge de boi gordo a para as praças de Araçatuba, Campo Grande, Três Lagoas, Cuiabá, Goiânia e Noroeste do Paraná, e Gonçalves et al. (2008), que mediram a efetividade do hedge e a direção da causação entre os preços futuro e a vista do boi gordo para a região do noroeste do Paraná.

É neste estado da arte que se insere o presente estudo, tendo em vista a importância da pecuária bovina para o estado do Rio Grande do Sul, pode-se encerrar a problemática acima exposta com o seguinte questionamento: qual a real eficiência na utilização do hedge como mecanismo de gerenciamento dos riscos relacionados à volatilidade dos preços de boi gordo para a região?

Para responder a esse problema de pesquisa, tem-se como objetivo geral examinar a eficiência da utilização do hedge como forma de atenuar os riscos oriundos das variações nos preços do boi gordo no Rio Grande do Sul. Especificamente, objetiva-se encontrar a razão ótima e a efetividade das operações de hedge dos contratos futuros de boi gordo na BM\&F-BOVESPA para o período de janeiro de 2005 a novembro de 2010.

Dessa forma, além de colaborar com o debate acadêmico no sentido de testar empiricamente uma ferramenta de análise de risco, o presente estudo também deixa uma contribuição para os pecuaristas do estado, os quais poderão utilizar tais informações como critério de decisão na elaboração de suas estratégias financeiras. 


\section{REGEX广UFSM}

GUERRA,DORR,FREITAS, v(11), no 11, p. 2462-2478 , JUN, 2013.

Rev. Elet. em Gestão, Educação e Tecnologia Ambiental (e-ISSN: 2236-1170)

\section{METODOLOGIA}

Para promover uma análise empírica acerca dos cálculos da razão ótima e da efetividade hedge, serão apresentados a seguir os elementos básicos à compreensão da aplicabilidade da teoria do portfólio na análise em questão, bem como os procedimentos econométricos necessários por se tratar de uma base de dados em séries temporais.

\section{Referencial Metodológico}

Há diversas teorias disseminadas a respeito da análise da decisão do hedge. Dentre estas, a teoria do portfólio ganha destaque à medida que, ao considerar que os hedgers, que são avessos ao risco, trabalham com um portfólio composto pelos ativos do mercado futuro e do mercado à vista, se observou a possibilidade de derivar o cálculo da efetividade e razão ótima do hedge a partir desta teoria.

Stein (1961 apud Silva 2001) foi um dos primeiros estudiosos a utilizar a teoria do portfólio neste intuito. A análise consiste em uma técnica geométrica simples de determinação simultânea de preços a vista e futuros, a partir da qual se tornou possível estimar a dimensão de posições em mercado a vista a ser cobertas por posições em mercados futuros, ou seja, a razão ótima do hedge.

Outros autores que tiveram grandes contribuições na análise em questão, dentre estes destacam-se Ederington (1979) e Myers e Thompson (1989), os quais obtiveram a relação ótima de hedge através do método dos Mínimos Quadrados Ordinários MQO e processos AR. Ederington (1979) estimou, através de MQO, uma regressão em nível que relacionava os preços à vista e futuros. Entretanto, é necessário que as variâncias estejam condicionadas aos momentos para encontrar uma regra de hedge ideal, ou seja, estas dependem das informações disponíveis no momento em que a decisão de hedge é tomada. Assim, considera-se a razão ótima de hedge uma relação entre a covariância do preço à vista e futuro $\left(\sigma_{p f}\right)$ e a variância do preço futuro $\left(\sigma_{f}^{2}\right)$, a qual é definida como:

$$
r=\frac{\sigma_{\mathrm{sf}}}{\sigma_{f}^{\mathrm{g}}}
$$

Esta estimação, realizada através da regressão simples ocasiona que tanto a covariância quanto a variância especificadas acima não são para momentos condicionais. Por esta razão, Myers \& Thompson (1989) desenvolveram um modelo generalizado para o qual as estimativas em questão consideram as informações disponíveis no momento da tomada de decisão e diminuem a possibilidade de regressão espúria. A equação abaixo descreve este modelo:

$$
p_{t}=\alpha_{0}+\delta f_{t}+\sum_{i=1}^{q} \alpha_{t} p_{t-i}+\sum_{j=1}^{q} \alpha_{q+j} f_{t=j}+\varepsilon_{t}
$$

onde, $p_{t}$ é o preço a vista no período $\mathrm{t} ; f_{t}$ é o preço futuro no período $\mathrm{t}$; $p_{t-1}$ é o preço a vista no período anterior; $f_{t-1}$ é o preço futuro no período anterior e $q$ o número de defasagens do 


\section{REGETHFSM}

Rev. Elet. em Gestão, Educação e Tecnologia Ambiental (e-ISSN: 2236-1170)

modelo. Já $\square$ e $\square$ são coeficientes que devem ser estimados pela regressão, sendo o interpretado como a razão ótima de hedge, $\square$ o intercepto e $\square_{\mathrm{t}}$ um termo de erro.

Cabe ressaltar ainda que Myers e Thompson (1989), ao observar as séries de preços convencionalmente utilizadas, ou seja, as séries em nível, diferença e retornos, perceberam que estes modelos são extremamente restritos, o que os torna inconsistentes. Deste modo, os autores conduziram a transformação das séries a serem analisadas para estacionárias em diferença, para assim, tornar os resultados mais confiáveis.

Com relação à efetividade do hedge, segundo Hull (2004), é a proporção da variância eliminada por meio do hedge. Entretanto, como estes métodos envolvem regressão múltipla, não é correto obter a efetividade do hedge, através do coeficiente de determinação da regressão $\left(R^{2}\right)$. Assim, esta é calculada da seguinte forma:

$$
e=1-\frac{\operatorname{Var}\left(h^{*}\right)}{\operatorname{Var}(p)}
$$

onde $e$ é a efetividade do hedge; $\operatorname{Var}\left(\mathrm{h}^{*}\right)$ a variância na receita de um portfólio hedgeado na proporção ótima e $\operatorname{Var}(p)$ a variância da receita de um portfólio não hedgeado.

Além disso, o cálculo da efetividade do hedge também pode ser demonstrado da seguinte forma:

$$
e=\rho^{2}
$$

Ou seja, esta pode ser determinada pelo cálculo do quadrado de $\square$ que representa o coeficiente de correlação linear entre as variáveis preço a vista e preço futuro.

\section{Procedimento}

As variáveis que compõem o objeto do presente estudo apresentam-se distribuídas de forma a constituir processos estocásticos. Deste modo, serão realizados os testes da Função de Autocorrelação (FAC), do teste Dickey-Fuller Aumentado (ADF) e Phillip-Perron (PP), a fim de verificar a se as séries são estacionárias.

Além disso, depois de testada a estacionaridade do modelo será verificada existência de co-integração entre as séries. Sendo que, do ponto de vista econômico, duas varáveis são cointegradas quando têm uma relação de equilíbrio de longo prazo. Deste modo, "podemos pensar em um teste de co-integração como um pré-teste para evitar situações de 'regressão espúria'."1. 


\section{REGEXfUFSM}

Rev. Elet. em Gestão, Educação e Tecnologia Ambiental (e-ISSN: 2236-1170)

Cabendo ainda destacar que, para a existência de co-integração entre as séries temporais estas devem ter a mesma ordem de integração.

Dentre os testes de co-integração, destaca-se o teste de Johansen, o qual é um método que permite testar a presença de múltiplos vetores de co-integração em apenas um passo, além de possibilitar o teste de versões restritas dos vetores de co-integração. Neste contexto, faz-se também necessária a aplicação dos critérios de informação de Akaike (AIC) e Schwarz (SBC), a fim de determinar as ordens das defasagens e decidir quantas serão utilizadas.

Salienta-se ainda que, a constatação de que há existência de um equilíbrio de longo prazo entre as variáveis em questão não significa que o mesmo seja válido para o curto prazo. Sendo assim, deve-se incluir no modelo (em diferença) o mecanismo de correção de erros (MCE), o qual, de acordo com Gujarati e Porter (2011), pode ser usado para ligar o comportamento de curto prazo de uma variável com seus valores de longo prazo. O MCE é representado pelo modelo abaixo:

$$
\Delta Y_{t}=\beta+\beta_{1} \Delta X_{t}-\beta_{2} U_{t-1}+\varepsilon_{t}
$$

Outrossim, tendo como princípio os procedimentos econométricos acima descritos e os pressupostos requeridos pelo modelo de Myers e Thompson (1989), serão realizadas as verificações necessárias afim de selecionar o modelo empírico mais adequado tendo em vista o objeto do presente estudo.

\section{Modelos Econométricos}

Nesta subseção serão abordados os métodos utilizados para o cálculo da razão ótima e efetividade do hedge, os quais seguem a abordagem geral explanada na subseção 4.1. Assim, define-se o modelo abaixo para a obtenção da regra ótima de hedge:

$$
\Delta P_{t}=\propto+\delta \Delta F_{t}+\sum_{i=1}^{p} \beta \Delta P_{t-i}+\gamma \Delta F_{t-1}+u_{t}
$$

onde, $\Delta P_{t}=$ Preço à vista mensal do boi gordo em primeira diferença no momento $t ; \Delta F_{t}$ $=$ Preço futuro mensal do boi gordo em primeira diferença no momento $t ; \Delta P_{t-\tilde{i}}=$ Preço à vista 


\section{REGETUFSM}

Rev. Elet. em Gestão, Educação e Tecnologia Ambiental (e-ISSN: 2236-1170)

mensal do boi gordo em primeira diferença no momento $t-i ; \Delta F_{t-1}=$ Preço futuro mensal do boi gordo em primeira diferença no momento $t-1 ; u_{t}=$ Termo de erro.

É a partir da equação acima que é estimada a razão ótima de hedge, cujo valor é representado pelo parâmetro $\square$. Por conseguinte, torna-se fácil a obtenção de sua efetividade posto que esta é especificada através da equação (3) vista anteriormente.

A efetividade do hedge varia entre zero e um, assim, quando esta for igual a zero, não haverá correlação entre os preços, enquanto que se o valor de $\boldsymbol{e}$ for igual a um a efetividade será máxima, ou seja, as mudanças de preços serão perfeitamente correlacionadas.

Desta maneira, para a estimação da efetividade é necessário obter a série de retornos para uma posição não hedgeada.e a série de retornos para uma posição hedgeada. Sendo assim, para a obtenção do primeiro calcula-ser a diferença entre preço (à vista) de cada período em relação ao preço (à vista) no primeiro período.

$$
R=P t-P 1
$$

onde $R$ corresponde ao retorno das series não hedgeadas $P 1$ ao preço à vista no primeiro período.

Posteriormente, para calcular a série de retornos para uma posição hedgeada é adicionada à série da posição não hedgeada uma série de retornos de preços futuros, a qual é multiplicada pela razão ótima de hedge, obtida no procedimento anterior. Salienta-se ainda, que a série de retornos dos preços futuros é calculada da mesma forma que série de retornos dos preços à vista, conforme observado na equação abaixo.

$$
R h=(P t-P 1)-h^{*}(F t-F 1)
$$

onde $R h$ corresponde ao retorno das series hedgeadas; $P 1$ ao preço à vista no primeiro período;

$h$ à razão ótima de hedge e $F 1$ ao preço futuro no primeiro período.

Tendo realizado este procedimento, basta obter as variâncias para ambos os portfólios e, através da equação (3), calcular a efetividade.

\section{Fonte e Base de Dados}




\section{REGEXfUFS}

Rev. Elet. em Gestão, Educação e Tecnologia Ambiental (e-ISSN: 2236-1170)

Foram utilizadas fontes de informações de dados secundários da BM\&FBOVESPA disponível no site www.bmfbovespa.com.br, para os dados referentes aos preços futuros. Estes se encontravam em séries diárias, porém, conforme o argumento de Stoll e Whaley (1993 apud Martins \& Aguiar 2004), as freqüências de comercialização nos mercados físicos e futuros não são as mesmas, o que faz com que as mudanças de preços à vista e futuro não reflitam a mesma série de informações de mercado. Deste modo, fez-se necessária a transformação dos dados diários em mensais, a qual foi feita por meio da escolha de um dia da semana, escolheu-se quarta feira por ser o dia de maior liquidez, caso não houvesse pregão neste dia utilizou-se o dia seguinte ou anterior. Posteriormente, foi feita uma média aritmética das semanas que compõem o mês. Deste modo chegou-se a 67 observações mensais.

Os preços no mercado físico foram obtidos junto à AGROLINK, disponível no site www.agrolink.com.br. Estes são referentes ao preço médio do boi gordo no Estado do Rio Grande do Sul e já se encontravam em séries mensais, entretanto, estavam na unidade quilo de boi vivo, de modo que este foi multiplicado por 30 (trinta) a fim de fazê-lo equivalente ao da arroba negociada na BM\&F.

\section{RESULTADOS E DISCUSSÃO}

\section{Realização dos Procedimentos Econométricos}

Como mencionado na seção 4.2, o presente estudo baseia-se em variáveis que constituem um processo estocástico. Então, é necessária a realização de alguns testes econométricos, antes de se partir para os cálculos da efetividade e da razão ótima do hedge. Deste modo, serão utilizados os critérios de informação de Akaike e de Schwarz no intuito de identificar os processos auto-regressivos, e assim, definir o número de defasagens a ser utilizadas no modelo.

Os resultados obtidos a partir destes critérios podem ser observados na Tabela 1, na qual estão contidas as ordens dos processos auto-regressivos para todas as séries de preços semanais utilizadas no estudo. Para o caso de divergência entre estes resultados opta-se, embasado pelo princípio da parcimônia, pela utilização da menor defasagem indicada por um destes critérios.

Tabela 1. Resultados dos critérios de informação para as séries de preços semanais em nível

\begin{tabular}{lllll}
\hline \multicolumn{2}{l}{ Preço à Vista } & \multicolumn{3}{l}{ Preço Futuro } \\
\hline № de Defasagens & AIC & SBC & AIC & SBC \\
\hline 0 & 7.82059 & 7.8535 & 8.36586 & 8.39876 \\
\hline 1 & 4.92741 & $4.99322^{*}$ & 6.71496 & $6.78077^{*}$ \\
2 & $4.92364^{*}$ & 5.02236 & $6.71423^{*}$ & 6.81294 \\
3 & 4.92695 & 5.05858 & 6.71819 & 6.84981
\end{tabular}




\section{REGEX}

Rev. Elet. em Gestão, Educação e Tecnologia Ambiental (e-ISSN: 2236-1170)

GUERRA,DORR,FREITAS, v(11), no 11, p. 2462-2478 , JUN, 2013.

4

4.9255

5.09003

6.74801

6.91254

Fonte: Elaboração própria a partir do software Stata 10.

A partir destes resultados deve-se então testar a existência ou não de raiz unitária na série em nível, ou seja, atestar se as mesmas são estacionárias. Neste intuito, serão utilizados os testes da Função de Autocorrelação (FAC), Dickey-Fuller Aumentado (ADF) e Phillip-Perron (PP). Destaca-se ainda que, se o resultado do testes comprovar a ausência de estacionaridade, será necessário testar as séries em diferenças até que o problema seja solucionado.

Assim, nas Figuras 1 e 2 observam-se as FAC referentes às séries de preços à vista e futuro respectivamente:

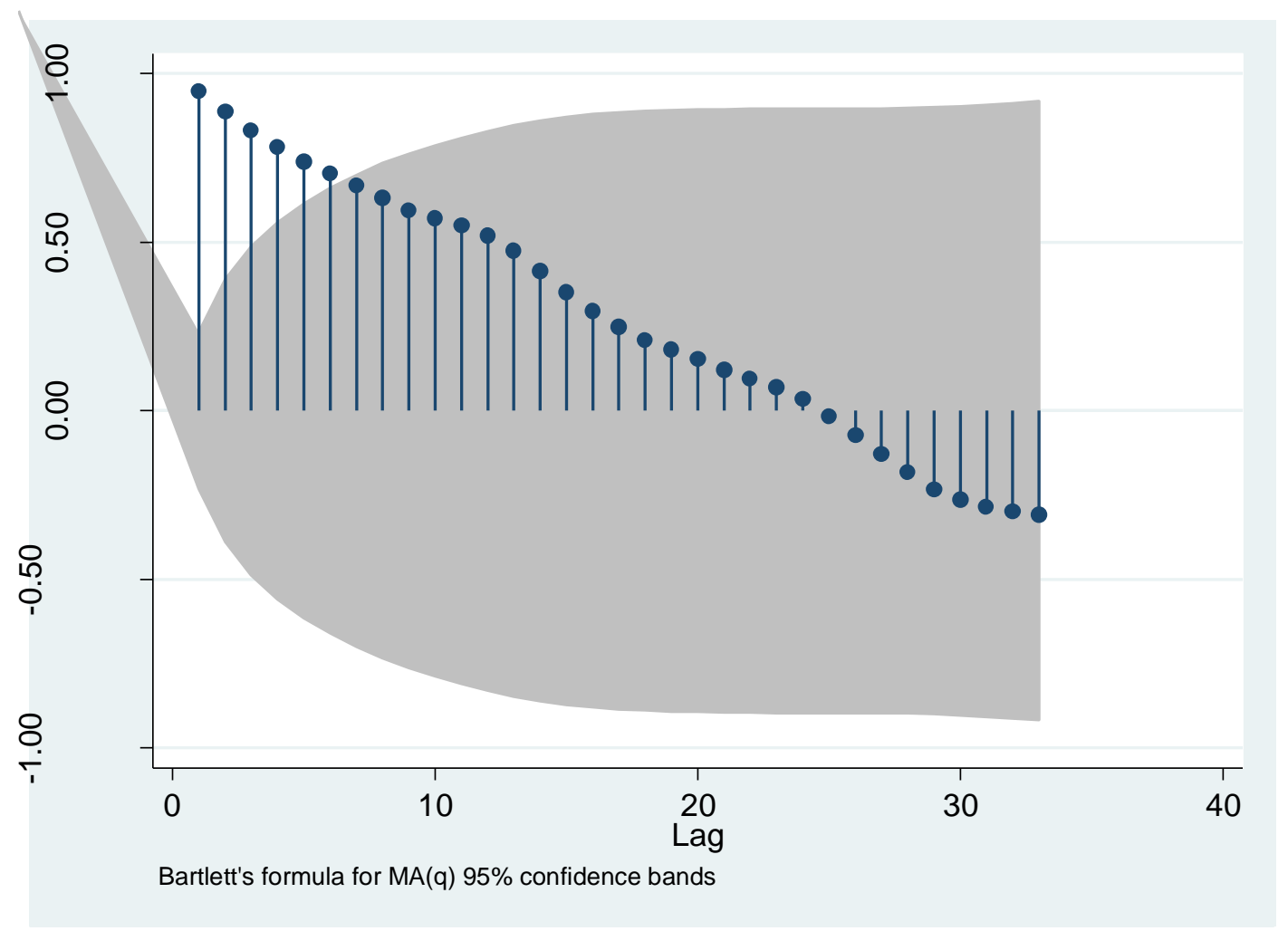

Figura 1. FAC da série de preços à vista mensal.

Fonte: Elaboração própria a partir do software Stata 10 
Rev. Elet. em Gestão, Educação e Tecnologia Ambiental (e-ISSN: 2236-1170)

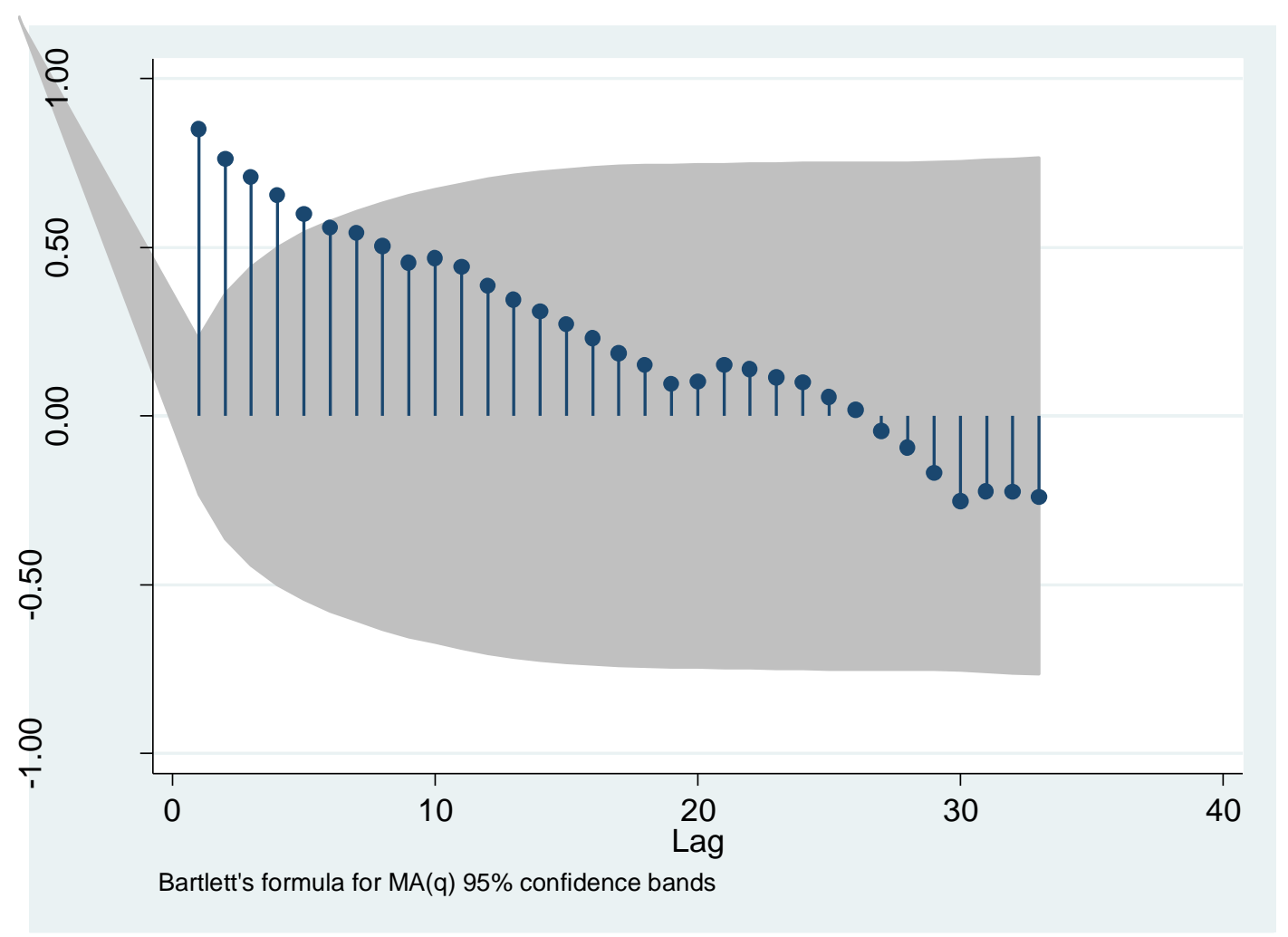

Figura 2. FAC da série de preços futuro mensal na BM\&F Fonte: Elaboração própria a partir do software Stata 10.

Como é possível perceber nas Figuras acima, o comportamento das séries analisadas demonstra que em todas as duas séries sofreram grande influência de seus valores passados, evidenciando um padrão típico de séries não estacionárias. Além disso, ao ser testada a existência de constante e tendência nas variáveis em nível, constata-se, a partir da Tabela 2, que ambas são estatisticamente significativas.

Tabela 2. Resultados dos testes de existência de constante e tendência nas séries em nível

\begin{tabular}{lll}
\hline Preço à Vista & & \\
\hline Variáveis & Estimativa dos Parâmetros & Valores de $t[\mathrm{p}]$ \\
\hline Constante & -243.615 & $-13.27[.000]$ \\
Tendência & 0.5388431 & $16.89[.000]$ \\
\hline Preço Futuro & & \\
\hline Variáveis & Estimativa dos Parâmetros & Valores de $t$ \\
\hline
\end{tabular}




\section{REGEXfUFSM}

GUERRA,DORR,FREITAS, v(11), no 11, p. 2462-2478 , JUN, 2013.

Rev. Elet. em Gestão, Educação e Tecnologia Ambiental (e-ISSN: 2236-1170)
Constante
$-290.0236$
$-9.93[.000]$
Tendência
0.6232609
$12.28[.000]$

Fonte: Elaboração própria a partir do software Stata 10

A realização dos os testes formais, a saber: teste Dickey-Fuller Aumentado e Phillip-Perron (PP) permite de ratificar as evidências visuais do padrão não estacionário dos processos em questão, os quais se encontram na Tabela $3^{2}$.

Tabela 3. Teste Dickey-Fuller Aumentado e Phillip-Perron para as séries de preços semanais em nível

\begin{tabular}{l|l|l}
\hline & Preço à vista & Preço futuro \\
Teste & Estatística $-\mathrm{t}$ & Estatística $-\mathrm{t}$ \\
$\mathrm{ADF}$ & -1.052 & -0.393 \\
$\mathrm{PP**}$ & -0.708 & -0.586 \\
\hline
\end{tabular}

Fonte: Elaboração própria.

*Valor crítico do teste de Dickey-Fuller ao nível de significância de $5 \%=-3,4215$.

**Valor crítico do teste de Phillip-Perron ao nível de significância de $5 \%=-2.877$.

Assim, tendo em vista os resultados acima descritos, bem como aqueles inicialmente sugeridos através das FAC's, e do modelo com constante e tendência, é possível constatar que, em nível, todas as variáveis possuem raiz unitária - uma vez que o ADF calculado é menor que o ADF crítico, o mesmo ocorrendo para o teste PP. Portanto, a partir deste diagnóstico, é necessária a diferenciação das séries I(d) vezes até que estas se tornem estacionárias. Desta forma, são realizados os testes de raiz unitária nas séries em primeira diferença, onde seguem nas Figuras 3 e 4, as Funções de Autocorrelação.

2 Valores obtidos a partir das defasagens identificadas através dos critérios AIC e SBC, expostos no anexo I, sendo estas $\mathrm{p}=1$ tanto para o preço à vista quanto preço futuro. 
REGETAFSM GUERRA,DORR,FREITAS, v(11), no 11, p. 2462-2478, JUN, 2013.

Rev. Elet. em Gestão, Educação e Tecnologia Ambiental (e-ISSN: 2236-1170)

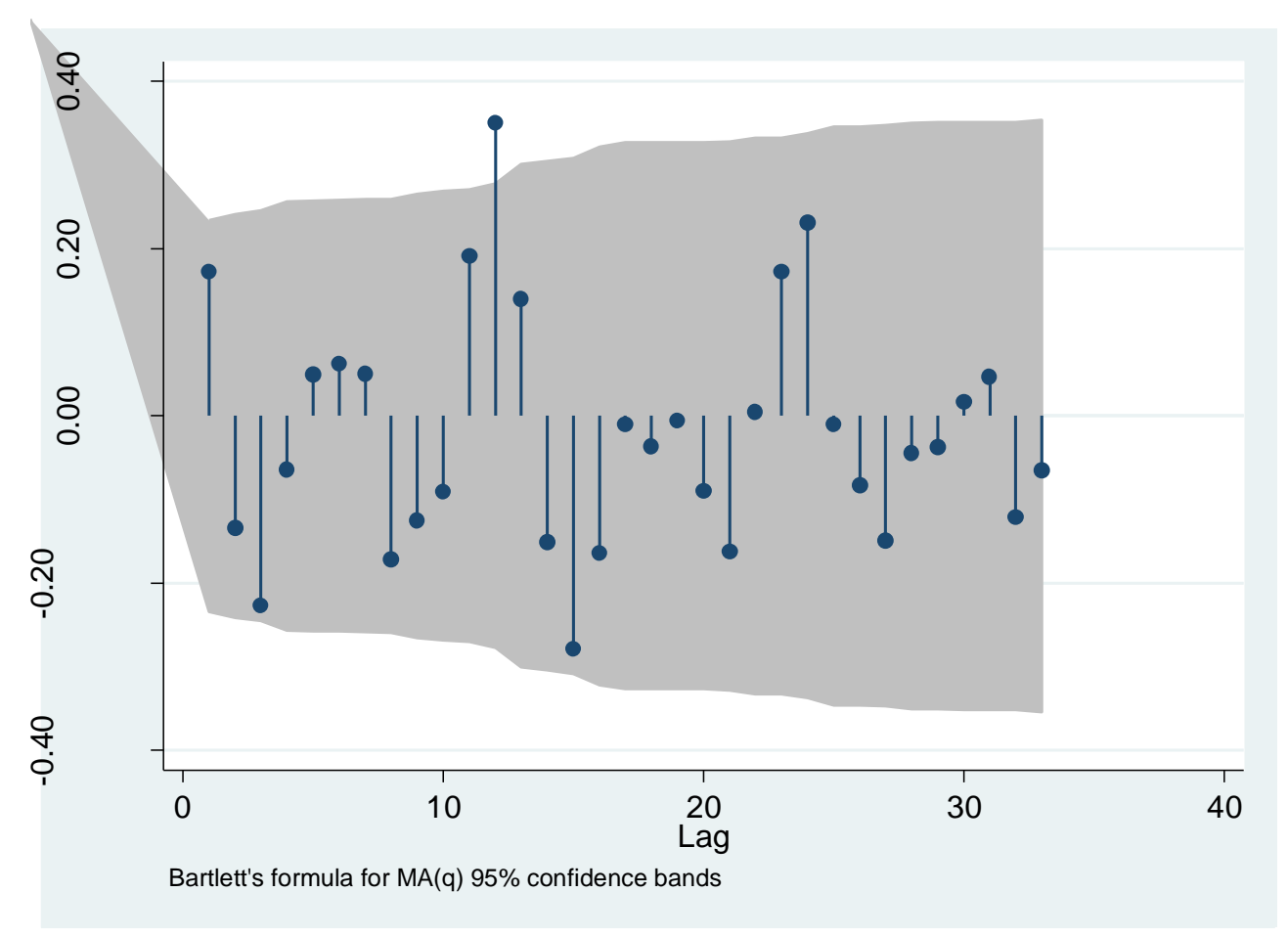

Figura 3. FAC da série de preços à vista mensal em primeira diferença Fonte: Elaboração própria a partir do software Stata 10. 


\section{REGEXALSM}

GUERRA,DORR,FREITAS, v(11), no 11, p. 2462-2478 , JUN, 2013.

Rev. Elet. em Gestão, Educação e Tecnologia Ambiental (e-ISSN: 2236-1170)

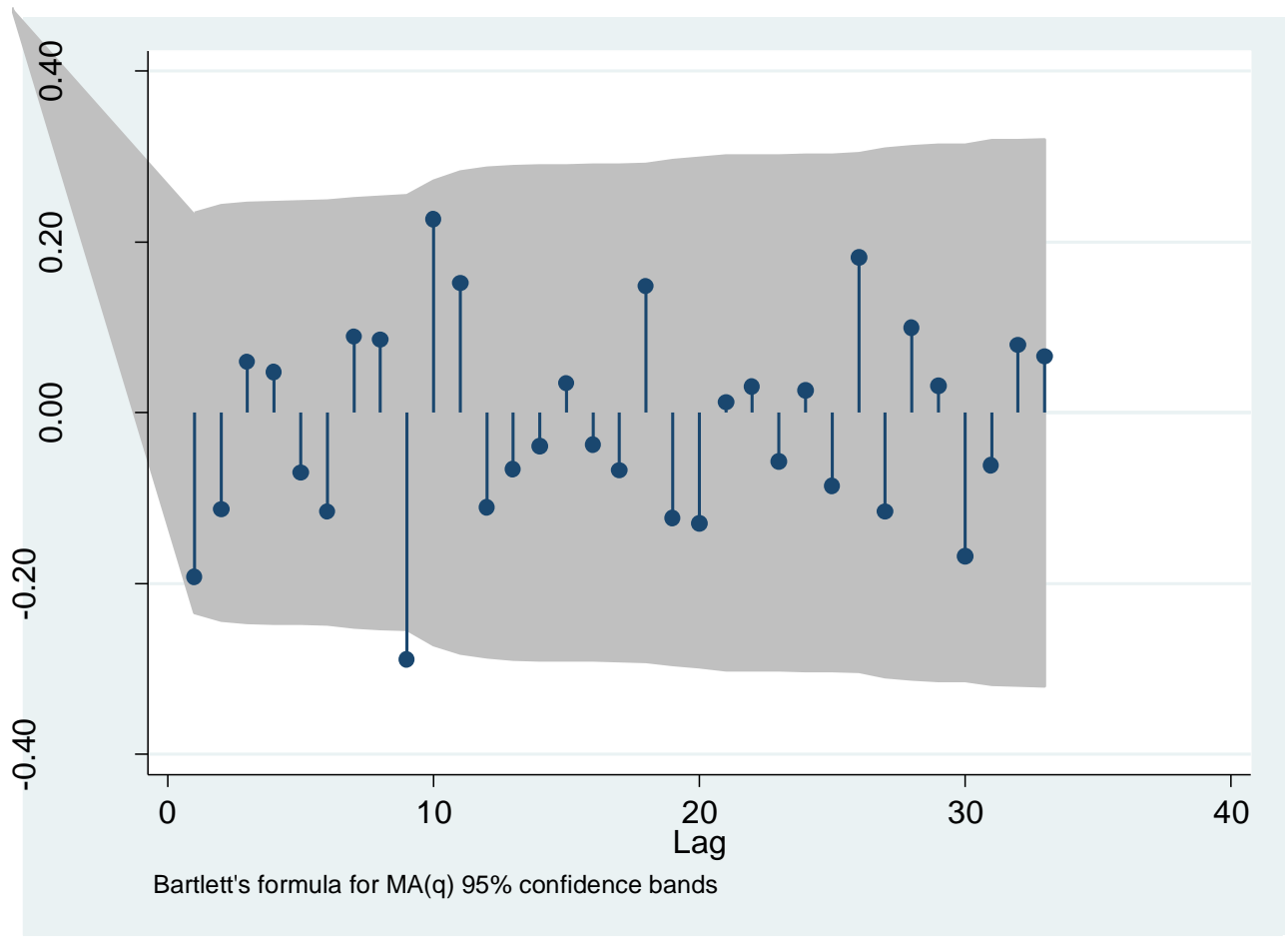

Figura 4. FAC da série de preços futuros mensal em primeira diferença Fonte: Elaboração própria a partir do software Stata 10.

Desta forma, partindo dos resultados demonstrados pelas Figuras da FAC para as séries em primeira diferença, é possível perceber a ausência de qualquer padrão sistemático destes valores ao longo do tempo e, com base nestes indícios estatísticos, é possível sugerir que as séries de preços analisadas são estacionárias em suas primeiras diferenças. No entanto, considerando o fato de que a FAC constitui um teste informal de raiz unitária, bem como que para seguir a proposta metodológica, serão efetuados os testes de Dickey-Fuller e Phillip-Perron, para assim ratificar os resultados propostos pelas FAC's.

Na Tabela 4 é possível verificar os resultados dos testes acima descritos. Cabe ainda destacar que para a obtenção dos dados apresentados nesta, foram definidas as ordens dos processos auto-regressivos através dos critérios de informação AIC e SBC. Caso estes divergissem quanto à melhor defasagem, primando pelo princípio da parcimônia na especificação das modelagens, optou-se por utilizar a menor, da mesma forma que para as séries em nível.

Tabela 4. Teste de Dickey-Fuller Aumentado e Phillip-Perron para as séries de preços semanais na primeira diferença

\begin{tabular}{l|l|l}
\hline & Preço à vista & Preço futuro \\
Teste & Estatística $-\mathrm{t}$ & Estatística $-\mathrm{t}$ \\
ADF* & -6.898 & -9.859
\end{tabular}




\section{REGEXfUFSM}

GUERRA,DORR,FREITAS, v(11), no 11, p. 2462-2478 , JUN, 2013.

Rev. Elet. em Gestão, Educação e Tecnologia Ambiental (e-ISSN: 2236-1170)

\begin{tabular}{l|l|l} 
PP** & -6.898 & -9.859 \\
\hline & Fonte: Elaboração própria. \\
& $*$ Valor crítico do teste de Dickey-Fuller ao nível de significância de $5 \%=-3,4215$. \\
$* *$ Valor crítico do teste de Phillip-Perron ao nível de significância de $5 \%=-2.877$.
\end{tabular}

Tendo como referência os resultados da Tabela 4, percebe-se que as séries não possuem raiz unitária em sua primeira diferença, pois, as estatísticas calculadas são menores que as críticas para ambos os testes. Esse resultado corrobora com aqueles obtidos a partir da FAC e dos demais testes realizados, além de convergir com a teoria em questão, a qual pressupõe que este tipo de série de preços é estacionária apenas em diferença.

Partindo destes resultados, os quais demonstram serem estas séries de preços integradas de mesma ordem, I(1), constata-se que o pré-requisito para a realização do teste de co-integração está satisfeito. Neste contexto, utiliza-se o teste de co-integração de Johansen, a fim de atestar existência de vetores de co-integração. Para isso, é preciso primeiramente encontrar o número de defasagens do vetor auto-regressivo, sendo estas obtidas através dos critérios de AIC e SBC. Se estes, divergirem quanto à extensão da defasagem, assim como nas análises anteriores utiliza-se a menor.

Tabela 5. Critérios de informação de Akaike e Schwarz para as séries

\begin{tabular}{lll}
\hline № de defasagens & AIC & SBC \\
\hline 0 & 14.5622 & 14.628 \\
1 & $\mathbf{1 1 . 3 8 7 4 *}$ & $\mathbf{1 1 . 5 8 4 9 *}$ \\
2 & 11.394 & 11.723 \\
3 & 11.4794 & 11.94 \\
4 & 11.4823 & 12.0746
\end{tabular}

Fonte: Elaboração própria a partir do software Stata 10.

Conforme os resultados descritos na Tabela 5, é possível identificar as defasagens para as séries estudadas. Considerando que os valores para o AIC e SBC, é possível estabelecer que o modelo possui uma defasagem. A partir disso, permite-se realizar o teste de co-integração de Johansen, que, através das estatísticas traço e autovalor máximo permitirá verificar a existência de vetores de co-integração.

A existência de co-integração depende do rank da matriz, se $r=0$, não há combinações lineares entre as variáveis, ou seja, não há co-integração. Se $r=$ pleno, a solução é dada por $n$ equações, sendo cada uma delas uma restrição independente da solução de longo prazo. Neste contexto, a estatística traço mostra-se útil à medida que através desta podemos testar a hipótese nula de que $r=0$ contra a hipótese alternativa de que $r \square 1$. Esta, juntamente com a estatística de máximo autovalor, que testa a hipótese nula de que $r=0$ contra a hipótese alternativa especifica 


\section{REGEX}

GUERRA,DORR,FREITAS, v(11), no 11, p. 2462-2478 , JUN, 2013.

Rev. Elet. em Gestão, Educação e Tecnologia Ambiental (e-ISSN: 2236-1170)

de que $r=1$, reúnem evidências estatísticas suficientes para encontrar o numero de vetores de cointegração do modelo.

Desta forma, os resultados da Tabela 5 permitem concluir que existe um vetor de cointegração no modelo sob análise. Isto pode ser verificado através do rank, o qual leva a rejeitar a hipótese nula de que não há nenhum vetor de co-integração $(r=0)$, ao considerar a estatística calculada maior do que a Tabelada ao nível de confiança de $95 \%$. Enquanto a hipótese nula de que existe um vetor de co-integração deve ser aceita ao nível de $95 \%$, pois, o valor desta estatística é menor do que a Tabelada, confirmando assim a existência de um vetor de co-integração no modelo.

Tabela 6. Teste de Co-integração de Johansen baseado no teste do Traço e no Teste de Máximo Autovalor

Teste do Traço

\begin{tabular}{llll}
\hline Hipótese Nula & Hipótese Alternativa & Estatística & Valor Crítico de 95\% \\
\hline$r=0$ & $r \square 1$ & 14.8177 & 15.41 \\
$r \leq 1$ & $r \square 2$ & 0.4684 & 3.76
\end{tabular}

Teste do Máximo Autovalor

\begin{tabular}{llll}
\hline Hipótese Nula & Hipótese Alternativa & Estatística & Valor Crítico de 95\% \\
\hline$r=0$ & $r=1$ & 14.3493 & 14.07 \\
$r \leq 1$ & $r=2$ & 0.4684 & 3.76 \\
\hline
\end{tabular}

Fonte: Elaboração própria a partir do software Stata 10.

O resultado apresentado no parágrafo acima, não é importante apenas para atestar a existência de um vetor de co-integração no modelo, mas também ponderar a influência de longo prazo destas variáveis. De tal modo, na Tabela 7 estão contidos os resultados acerca do modelo de longo prazo normalizado por Johansen para os preços à vista e futuro do boi gordo para as praças do Estado do Rio Grande do Sul.

Tabela 7. Resultado da relação de longo prazo entre o preço à vista e futuro

\begin{tabular}{lll}
\hline Variáveis & Estimativa dos parâmetros & Valores de $t$ \\
\hline Constante & 11.74244 & - \\
Preço à vista & 1.0000 & -
\end{tabular}




\section{REGEX广AFSM}

Rev. Elet. em Gestão, Educação e Tecnologia Ambiental (e-ISSN: 2236-1170)
Preço Futuro
0.7779674
$-8.94[.000]$

Fonte: Elaboração própria a partir do software Stata 10.

Ademais, a partir da Tabela 7 pode-se concluir que uma variação de $\mathrm{R} \$ 1,00$ no preço à vista, gera uma variação de $\mathrm{R} \$ 0,78$ no preço futuro do boi gordo no longo prazo. Há portanto, uma relação estatística muito próxima entre os dois vetores.

A Tabela 8 trás os resultados do mecanismo de correção de erros (MCE). Nota-se que ao sinal do termo do erro defasado é negativo, conforme o esperado. Isso indica que a série não é explosiva. Assim, os resultados estimados permitem dizer que, aproximadamente, $11 \%$ das discrepâncias dos preços efetivos e esperados do contrato de boi gordo da BM\&F são corrigidas dentro de um mês para série em questão. Esse resultado permite caracterizar a série convergente e não explosiva.

Tabela 8. Aplicação do Mecanismo de Correção de Erros (MCE)

\begin{tabular}{lll}
\hline Variáveis & Estimativa dos parâmetros & $\mathrm{P}>|\mathrm{z}|$ \\
\hline Constante & 0.5974406 & 0.072 \\
Preço futuro & 0.1937005 & 0.095 \\
MCE & -0.1172928 & 0.072
\end{tabular}

Fonte: Elaboração própria a partir do software Stata 10.

\section{Cálculo da Razão Ótima de Hedge}

Conforme foi constatado na seção 5.1, as séries a serem analisadas pelo presente estudo não são estacionárias em nível, deste modo, para realizar os cálculos quanto à razão ótima de hedge serão empregadas as séries em primeira diferença. Além disso, não serão utilizadas as defasagens, conforme indicado pela identificação da ordem dos processos auto-regressivos contidas no Anexo III, sendo estas foram obtidas considerando-se o modelo em primeira diferença.

Além disso, o calculo da razão ótima de hedge será feito a partir da fórmula (6), na qual se tem estimados os coeficientes $\square, \square, \square, \square$. Como já mencionado na seção 4.3 , o coeficiente $\square$ é de especial interesse para este estudo, pois representa a razão ótima de hedge. Assim, na Tabela 10 são apresentados os resultados estimados.

Tabela 10. Resultado da regressão (10) por MQO para obtenção da razão ótima de hedge 


\section{REGEX}

GUERRA,DORR,FREITAS, v(11), no 11, p. 2462-2478 , JUN, 2013.

Rev. Elet. em Gestão, Educação e Tecnologia Ambiental (e-ISSN: 2236-1170)

\begin{tabular}{lcl}
\hline Razão ótima de hedge & & \\
\hline Variáveis & Estimativa dos Parâmetros & Valores de $t[\mathrm{p}]$ \\
\hline Constante $(\square)$ & 0.4345276 & $1.29[.201]$ \\
Razão Ótima $(\square)$ & 0.0560582 & $1.12[.268]$ \\
Estat. F. F( 1,68$)=$ & $1.25[.018]$ & \\
\hline
\end{tabular}

Fonte: Elaboração própria.

Na Tabela 10 é possível averiguar que a constante só é significativa a $20,1 \%$. Contudo, o interesse particular, conforme já ressaltado, é no coeficiente a $\square \square \square$ razão ótima), o qual se mostra significativo apenas a níveis de confiança acima de $26,8 \%$. Esse resultado revela que para se ter a minimização dos riscos, inerentes às oscilações nos preços, são necessários que 5,61\% do total de recursos possuídos pelo hedger sejam protegidos via operações de hedge.

\section{Cálculo da Efetividade do Hedge}

Definido o percentual da razão ótima de hedge, parte-se para o cálculo da efetividade destas operações. A efetividade do hedge, obtida através da equação (4) é de $12 \%$. Esse valor do hedge se mostrou pouco efetivo como ferramenta de minimização de riscos, já que apenas $12 \%$ dos riscos de preço podem ser dissipados através destas operações no mercado futuro da BM\&FBOVESPA.

\section{CONCLUSÕES}

Para os produtores de boi gordo do Rio Grande do Sul, assim como os demais pecuaristas do Brasil, o gerenciamento dos riscos oriundos das oscilações nos preços pode proporcionar uma expressiva diminuição dos mesmos. Nesse contexto, evidencia-se a importância da identificação de alternativas para a contenção da volatilidade dos preços do boi gordo, dentre as quais, se destacam as operações de hedge.

Assim, através do presente estudo, buscou-se quantificar o nível de eficiência, bem como a proporção ótima de boi gordo produzido no Estado que deveria ser protegido por meio das operações no mercado futuro. Para tanto, foi realizada uma variedade de testes econométricos a partir dos quais foi possível perceber que o boi gordo gaúcho possui uma efetividade relativamente baixa, apenas $12 \%$ dos casos as operações de hedge seriam eficientes na redução do risco oriundo das oscilações nos preços do produto. Quanto à sua razão ótima, ou seja, o percentual de produção a ser negociado no mercado futuro, ficou em torno de 5,61\%, ressaltando-se ainda que esta só é significativa a níveis de confiança superiores a $26,8 \%$, o que 


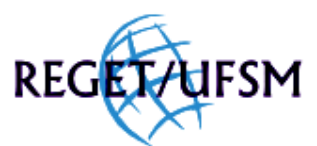

GUERRA,DORR,FREITAS, v(11), no 11, p. 2462-2478 , JUN, 2013.

Rev. Elet. em Gestão, Educação e Tecnologia Ambiental (e-ISSN: 2236-1170)

leva a concluir não ser o hedge uma boa ferramenta de gerenciamento de riscos para pecuaristas gaúchos.

Apesar do resultado apontar que na região em estudo, a utilização de operações de hedge não se mostraram efetivas para o gerenciamento de riscos, é importante destacar que no segmento agropecuário existem algumas particularidades, a se destacar: o produtor rural é um tomador de preços e a produção é altamente dependente de condições climáticas. Assim para se manter de forma sustentável na atividade, os produtores rurais precisam gerenciar custos e riscos, o que depende basicamente de estratégias gerenciais bem definidas. E entre estas estratégias, a transferência do risco deve ser utilizada, assim a utilização de contratos futuros deve ser analisada caso a caso, dependendo da realidade de cada produtor rural.

\section{REFERENCIAS BIBLIOGRÁFICAS}

ALVES, W. B. Análise da efetividade e da razão ótima do hedge do boi gordo e do cross-hedge do bezerro. Santa Maria: UFSM, 2010. Monografia (Graduação em Ciências Econômicas), Universidade Federal de Santa Maria, 2010.

INSTITUTO BRASILEIRO DE GEOgRAFIA E ESTATístICA - IBGE. IBge Estados - Pesquisa Pecuária 2011. Disponível em: <http://www.ibge.gov.br/> Acesso em: 20 out. 2012.

EDERINGTON, L. H. The hedging performance of the new futures markets. Journal of Finance, v. 34, n. 1, p. 157-170, 1979.

GUJARATI, D.; PORTER, D. C. Econometria Básica. 5a edição - Porto Alegre: AMGH, 2011

MARKOWITZ, H. M. “Portfolio selection”. The Journal of Finance, Berkeley, v. 7, n. 1, p. 77-91, Mar 1952.

MARTINS, A. G.; AGUIAR, D. R. D. Efetividade do hedge de soja em grão com contratos futuros de diferentes vencimentos na Chicago Board of Trade. Revista de Economia e Agronegócio, v. 2, n. 4, p. 449-472, 2004.

MONTEIRO, W. F., L. et al. A não efetividade do hedge para o boi gordo. In: CONGRESSO BRASILEIRO DE ECONOMIA E SOCIOLOGIA RURAL, XLVIII, 2011, Campo Grande. Anais... Campo Grande: Sociedade Brasileira de Economia, Administração e Sociologia Rural, 2011. p. 19.

GONÇALVES, D. F. et al. Co-integração, causalidade e efetividade do hedge para preços do contrato de boi gordo para noroeste do Paraná. Informe Gepec, v. 12, p. 11-25, 2008.

HULL, J. Fundamentos dos Mercados Futuros e de Opções 5. ed. (português, inglês) São Paulo: Bolsa de Mercadorias \& Futuros, 2004.

MYERS, R. J.; THOMPSON, S. R. Generalized optimal hedge ratio estimation. American Journal of Agricultural Economics, v. 71, n. 4, p. 858-867, 1989.

SILVA, A. R. O. A efetividade do hedge e do cross-hedge de contratos futuros para soja e derivados. Viçosa: UFV, 2001. Dissertação (Mestrado em Economia Rural), Universidade Federal de Viçosa, 2001. 